Document downloaded from:

http://hdl.handle.net/10251/58236

This paper must be cited as:

Baselga Moreno, S.; García-Asenjo Villamayor, L.; Garrigues Talens, P. (2013). Submillimetric GPS distance measurement over short baselines: case study in inner consistency. Measurement Science and Technology. 24(7):750011-750018. doi:10.1088/0957-0233/24/7/075001.

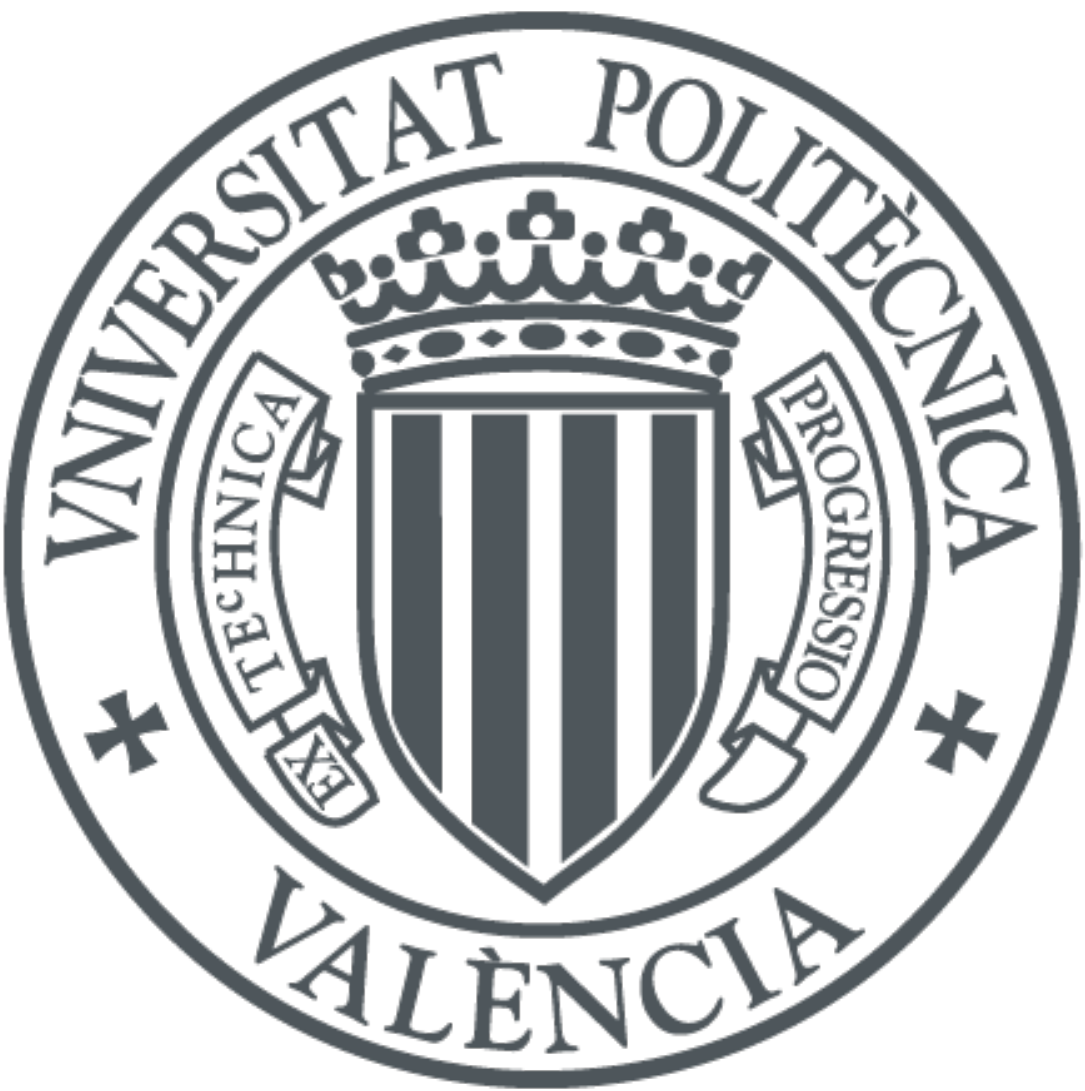

The final publication is available at

http://dx.doi.org/10.1088/0957-0233/24/7/075001

Copyright IOP Publishing: Hybrid Open Access

Additional Information 


\title{
Submillimetric GPS distance measurement over short baselines: case study in inner consistency
}

\author{
S. Baselga, L. García-Asenjo and P. Garrigues \\ Dpto. Ing. Cartográfica, Geodesia y Fotogrametría, Universidad Politécnica de Valencia, \\ Camino de Vera s/n, 46022 Valencia, Spain \\ E-mail: serbamo@cgf.upv.es (S. Baselga)
}

\begin{abstract}
Distance determination in open air with submillimetric accuracy is a challenging task usually carried out with the use of submillimetric distancemeters and costly observation campaigns. The present paper represents a first step in the research of the potential use of GPS for submillimetric distance determination for distances up to a few hundred metres consisting in the evaluation of GPS distance determination reproducibility. As it will be concluded, reliable submillimetric precision is attainable after some hours of observation if the same equipment in both baseline ends is used, even considering that there still remain some long-term systematic effects of a few tenths of a millimetre. The need for precise absolute antenna calibration values is also shown to be critical for submillimetric distance reproducibility.
\end{abstract}

Keywords: distance measurement, short baseline, submillimetric accuracy, GPS metrology

\section{Introduction}

Distance measurement from few metres up to a few hundred metres in open air with few tenths of millimetre accuracy is a challenge at present time (Wallerand et al 2008). Traditionally, submillimetric distance determination has been only possible after costly observation campaigns with dedicated electronic distancemeters (EDM) like the MEKOMETER ME5000, which provides $0.2 \mathrm{~mm}+0.2 \mathrm{ppm}$ accuracy, after careful calibration of the instrument with quartz interferometers (Bell 1992, Lassila et al 2003, Jokela and Häkli 2006). At present, new instruments are being developed to go beyond the now out-of-production classic submillimetric EDMs, among others new frequency comb based EDMs (Doloca et al 2010, Hyun et al 2009, Schuhler et al 2006).

GPS observation and processing is usually performed for geodetic or surveying purposes, which involves the determination of coordinates either in relative (differential GPS) or absolute mode (Precise Point Positioning) but except very rare exceptions (Koivula et al 2012) no optimization of GPS procedures are done in order to exploit its capabilities in distance determination.

The usage of GPS for distance determination over short baselines with submillimetre accuracy is an appealing possibility that still needs much research. As a first step, the present paper focuses on the study of GPS distance determination reproducibility, i.e. the analysis of inner consistency of GPS distance determination. Precise reproducibility is a necessary though not sufficient condition for the eventual use of GPS for submillimetric accuracy determination. Only if GPS lengths turn out to have a precise reproducibility it will be convenient to compare them to a length pattern traced to the definition of the SI metre (absolute scale).

At the UPV campus a calibration baseline has been recently set up and absolute scale from the Nummela baseline - see Jokela and Häkli (2006) - has been transferred after an observation campaign with the MEKOMETER ME5000 EDM. The expected baseline stability at the submillimetre level is currently being investigated. In view of the good GPS reproducibility results obtained in this paper, comparison at the submillimetre level between GPS and absolute distances remain now as a sensible open question for further research. 


\section{Initial assumptions}

Regarding GPS noise characterization, it is well-known that modern receivers provide phase observations with submillimetre level noise (Bona and Tiberius 2000). However, some works point out that multipath effects are at least an order of magnitude larger and conclude that multipath plays a major role in short baselines (Amiri-Simkooei and Tiberius 2007). Other periodic effects may also be experienced due to orbit mismodelling, deficiencies in EOP tide models (Griffits and Ray 2012) and errors or approximations in the antenna or radome calibration (Ray et al 2008).

With respect to GPS observation time, there are many studies and corresponding recommendations for the case of coordinate determination but none for the particular problem of distance determination. We give two examples: Hughes et al (2006) in their short baseline determination of coordinates recommend 10 hour for each vector being $3 \mathrm{~h}$ a possible compromise between time and precision; and Firuzabadi and King (2012) conclude that sessions as short as $6 \mathrm{~h}$ can be nearly as precise as a 24-h session. We will later see whether these recommendations may also apply to the case of distance determination.

Regarding the different GPS processing strategies, it is fairly obvious that for the case of our short baseline - distance no longer than some $100 \mathrm{~m}$ - it is optimum to use only $\mathrm{L}_{1}$ carrier phase observables (since the signal is stronger than $L_{2}$ or any other combination of $L_{1}$ and $L_{2}$ ), no ionospheric or tropospheric models are needed (delays cancel satisfactorily for this distance range) and one must use absolute antenna calibrations. This is also the proposal followed in the preceding study of Koivula et al (2012). However, their distance determination study is only based on four campaigns of two 24-h sessions of GPS data. We want to considerably extend the period of observation up to a whole year using some of the most stable stations of the IGS global network (Dow et al 2009), EUREF Permanent GNSS Network (EPN) (Bruyninx et al 2009) and CORS network (Snay and Soler 2008).

\section{Experiments}

Among the IGS, EPN and CORS tracking stations we searched for pairs of them separated some metres (the range of distances we are interested in) and with potentially highly stable monumentation and preferably clear surroundings (to avoid multipath). We should consider that most of the stations belonging to those networks may not be stable up to the $0.1 \mathrm{~mm}$ level (e.g. antennas installed on building roofs or other structures may suffer from movements above the submillimetre level and were discarded in favour of concrete pillars or masts with concrete foundations). Finally, we selected for analysis the pairs displayed in Table 1.

Table 1. Baseline features.

\begin{tabular}{ccccccc}
\hline $\begin{array}{c}\text { Baseline } \\
\text { (network) }\end{array}$ & $\begin{array}{c}\text { Length } \\
\text { (m) }\end{array}$ & $\begin{array}{c}\text { Azimuth } \\
\text { (gon) }\end{array}$ & $\begin{array}{c}\text { Approx. } \\
\text { lat } / \text { lon }\end{array}$ & Antennas (radomes) & $\begin{array}{c}\text { Avail. } \\
\text { calibration }\end{array}$ & Monuments \\
\hline $\begin{array}{c}\text { BAY5 } \\
\text { BAY6 }\end{array}$ & 29.976 & 63.37 & $55^{\circ} /-162^{\circ}$ & $\begin{array}{c}\text { 2 TRM41249USCG } \\
\text { (SCIT) }\end{array}$ & $f$ (az,elev) & $\begin{array}{c}\text { Concrete } \\
\text { pillars and } \\
\text { steel masts }\end{array}$ \\
\hline $\begin{array}{c}\text { LNC1 } \\
\text { LNC2 } \\
\text { (CORS) }\end{array}$ & 27.326 & 299.17 & $39^{\circ} /-121^{\circ}$ & $\begin{array}{c}\text { 2 ASH701945E_M } \\
\text { (SCIT) }\end{array}$ & $f$ (az,elev) & $\begin{array}{c}\text { Concrete } \\
\text { pillars }\end{array}$ \\
\hline $\begin{array}{c}\text { CAGL } \\
\text { CAGZ } \\
\text { (EPN) }\end{array}$ & 2.524 & 187.05 & $39^{\circ} / 9^{\circ}$ & $\begin{array}{c}\text { TRM29659.00 (NONE) } \\
\text { JPSREGANT_DD_E (NONE) }\end{array}$ & $f$ (az,elev) & $\begin{array}{c}\text { Concrete } \\
\text { pillars }\end{array}$ \\
\hline $\begin{array}{c}\text { MEDI } \\
\text { MSEL } \\
\text { (EPN) }\end{array}$ & 27.052 & 320.24 & $44^{\circ} / 11^{\circ}$ & $\begin{array}{c}\text { TRM29659.00 (NONE) } \\
\text { LEISR399_INT (NONE) }\end{array}$ & $f($ elev) & $\begin{array}{c}\text { Concrete } \\
\text { pillar and } \\
\text { steel mast }\end{array}$ \\
\hline $\begin{array}{c}\text { SUTH } \\
\text { SUTM } \\
(\text { IGS) }\end{array}$ & 142.141 & 180.80 & $-32^{\circ} / 20^{\circ}$ & $\begin{array}{c}\text { ASH701945G_M (NONE) } \\
\text { AOAD/M_T (NONE) }\end{array}$ & $f$ (az,elev) & $\begin{array}{c}\text { Concrete } \\
\text { pillars }\end{array}$ \\
\hline
\end{tabular}


We used final ephemerides as provided by the IGS (Dow et al 2009) and the most up-to-date IGS antenna absolute calibration model (igs08_1673.atx at the moment). We formed double-differenced $\mathrm{L}_{1}$-carrier phases and obtained solutions for every 1-h span of observations (120 epochs) during the entire year 2011. For the purpose of systematic effect analysis it also became pertinent to analyze some data of year 2010.

\section{Results and discussion}

For the 24 distances obtained for a typical day processing of a baseline (each distance computed from $1 \mathrm{~h}$ of observations) we show in figure 1 their differences with respect to the daily mean. In particular, the figure refers to baseline BAY5 - BAY6 and day 124 of year 2011; however, results are in general quite similar for different days and baselines, with distance values varying along the day in ranges of 1 to $4 \mathrm{~mm}$.

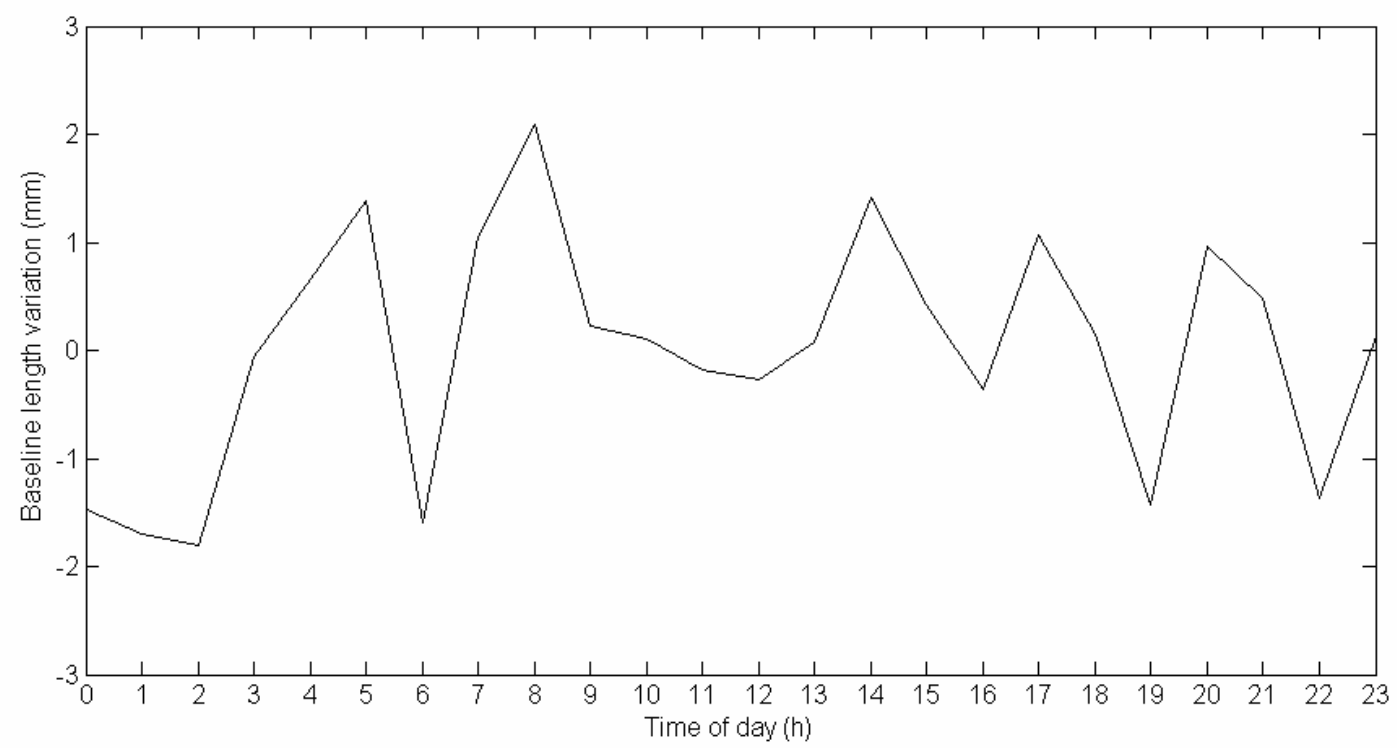

Figure 1. BAY5 - BAY6 baseline length variation for a 24-h period.

It is pertinent to question whether some systematic errors are affecting the solution, in particular whether some periodic effects are forcing the solution to oscillate. By inspecting the solution for several days a strong correlation between consecutive days is found to be evident. A closer look reveals the existence of a clear repetition pattern with period apparently coincident with the sidereal day. Therefore, if we plot now the solution for day 124 along with day 139 (15 days later), both with respect to the mean of the first day, we can see the second signal to be quite similar to the first but approximately advanced $15 \times 4=60 \mathrm{~min}$, figure 2 .

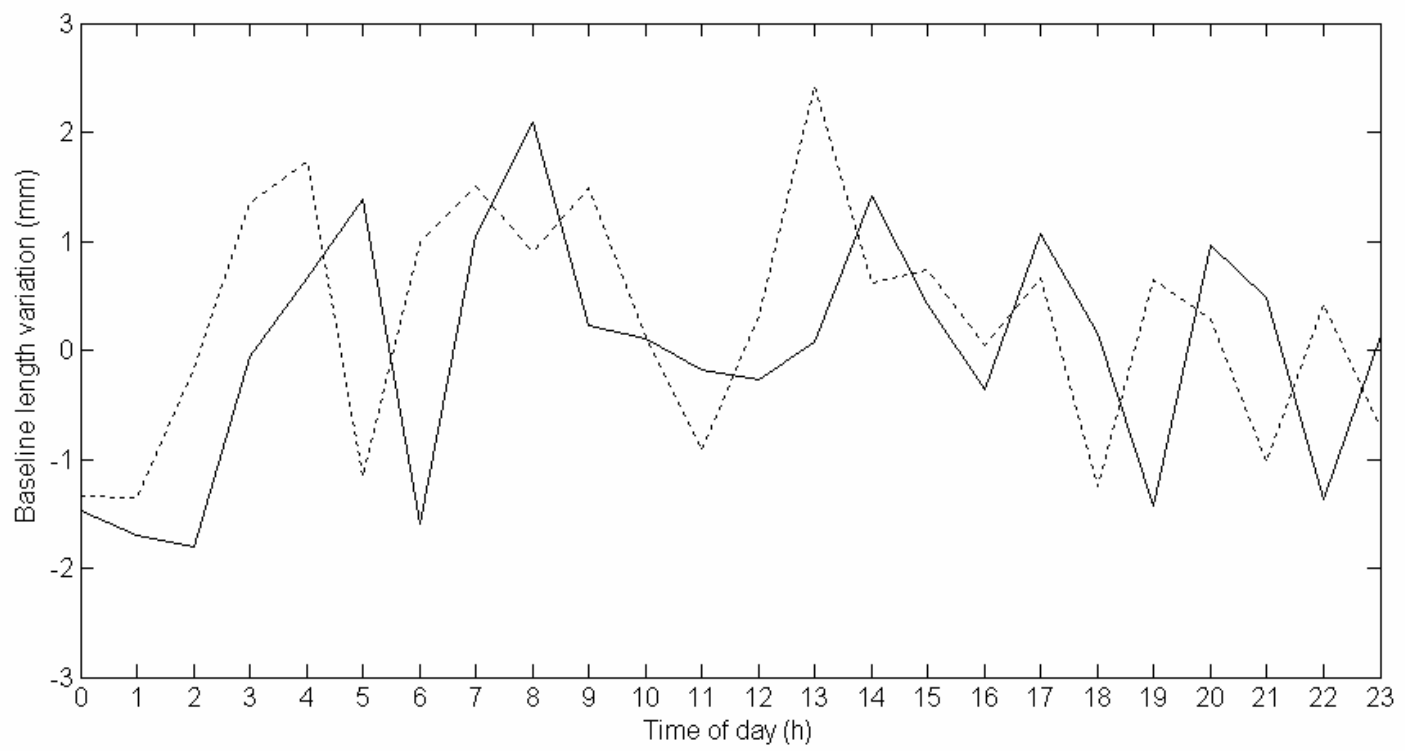


Figure 2. BAY5 - BAY6 baseline length variation for two 24-h periods: day 139 (dotted line) follows the same pattern as day 124 (solid line) with a 1-h advance.

The individual components of the baseline - ENU coordinates - undergo similar variations - see figure 3 - although it can be noted that vertical precision is obviously lower. We can also note that when obtaining only the baseline length some of the site-dependent effects are partly compensated.
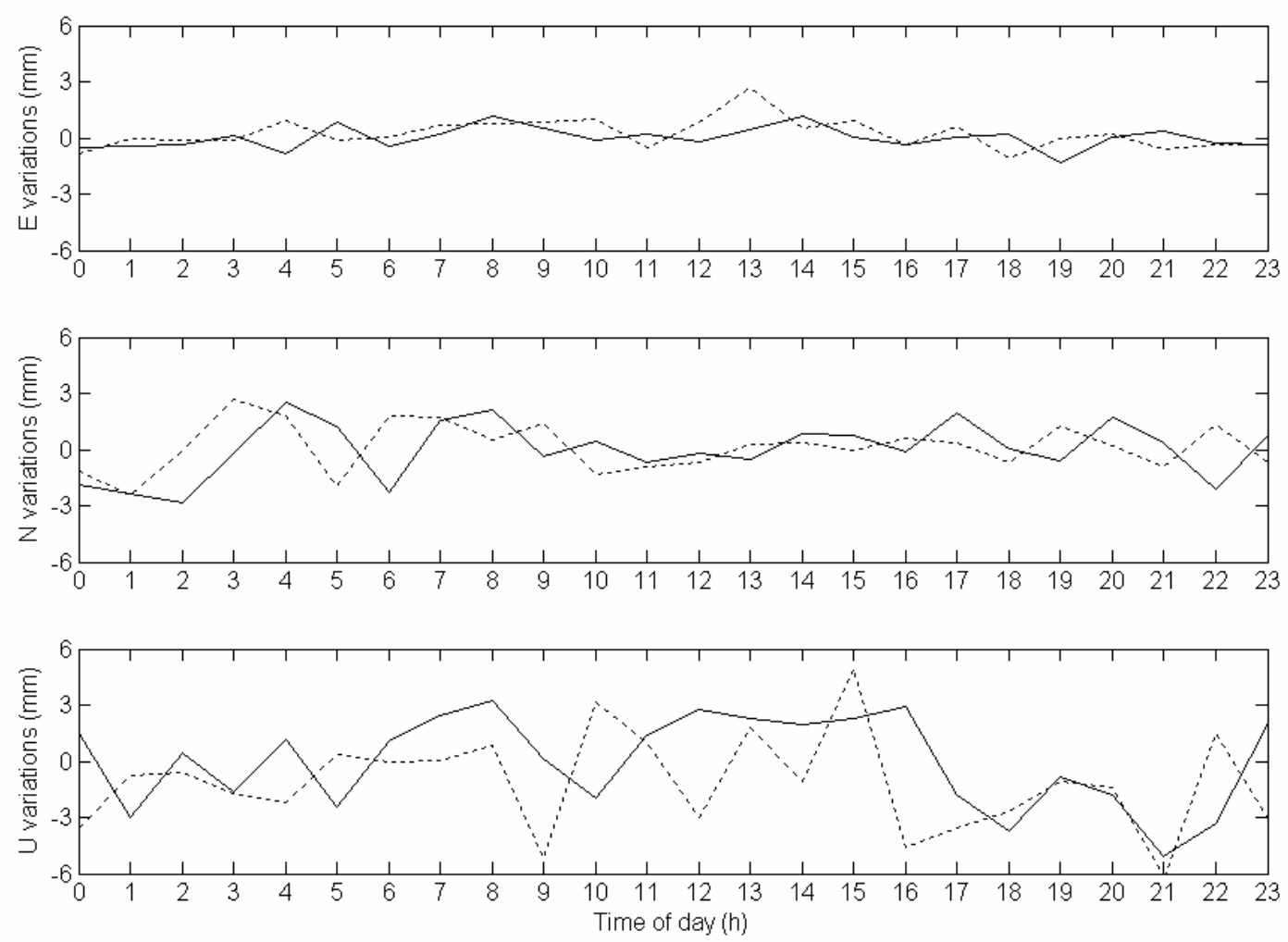

Figure 3. BAY5 - BAY6 ENU coordinate variations for two 24-h periods: day 139 (dotted line) and day 124 (solid line).

This behaviour exists, more or less evidently, for all baselines and periods of the year (figure 4 shows other example), and may suggest effects related to the constellation geometry (repeated for the baseline every sidereal day). Remember, however, that these GPS stations were selected so as to be potentially free from multipath.

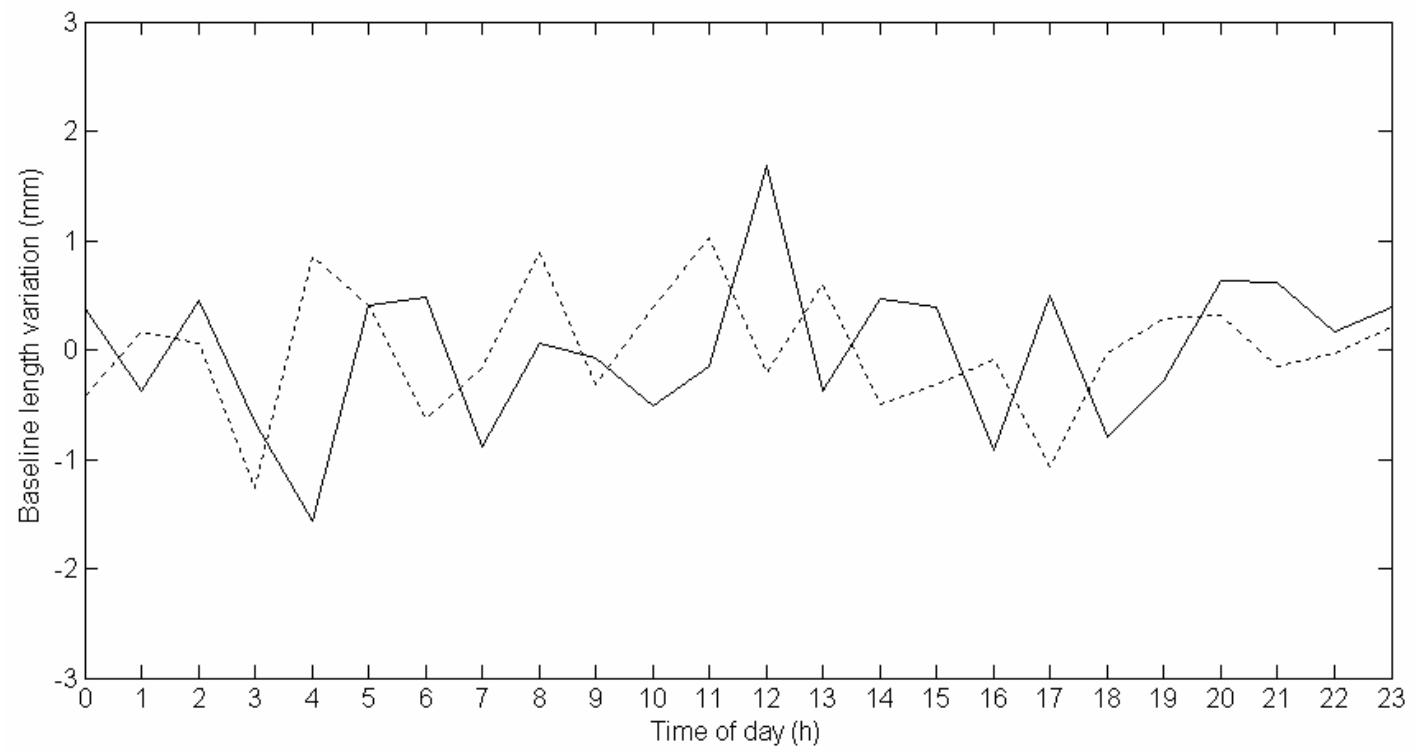


Figure 4. CAGL - CAGZ baseline length for two 24-h periods: day 53 (dotted line) follows the same pattern as day 38 (solid line) with a 1-h advance.

The existence of this periodic signal can also be confirmed by the following procedure: if the existent noise was purely Gaussian then we could expect for baselines computed with 1-h data and 2-h data to have respectively experimental standard deviations $\sigma_{1}$ and $\sigma_{2}=\sigma_{1} / \sqrt{2}$; and in general for an $n$-h data baseline $\sigma_{n}=\sigma_{1} / \sqrt{n}$, according to the uncertainty propagation law. Conversely, if a significant periodic signal (of amplitude no smaller than the Gaussian noise) of period $p$ exists then the experimental standard deviations found do not decrease continuously according to the Gaussian uncertainty propagation law, but diminish only until $\sigma_{\mathrm{p}}=\sigma_{1} / \sqrt{\mathrm{p}}$. In figure 5 we display the experimental standard deviation values obtained for the former baseline distance determinations with 1-h, 2-h, 3-h... data from the processing of all the corresponding baselines in a year $(24 \times 365$ 1-h baselines, $12 \times 365$ 2-h baselines, $8 \times 365$ 3-h baselines). They are, therefore, truly experimental not theoretical values obtained for the year 2011.

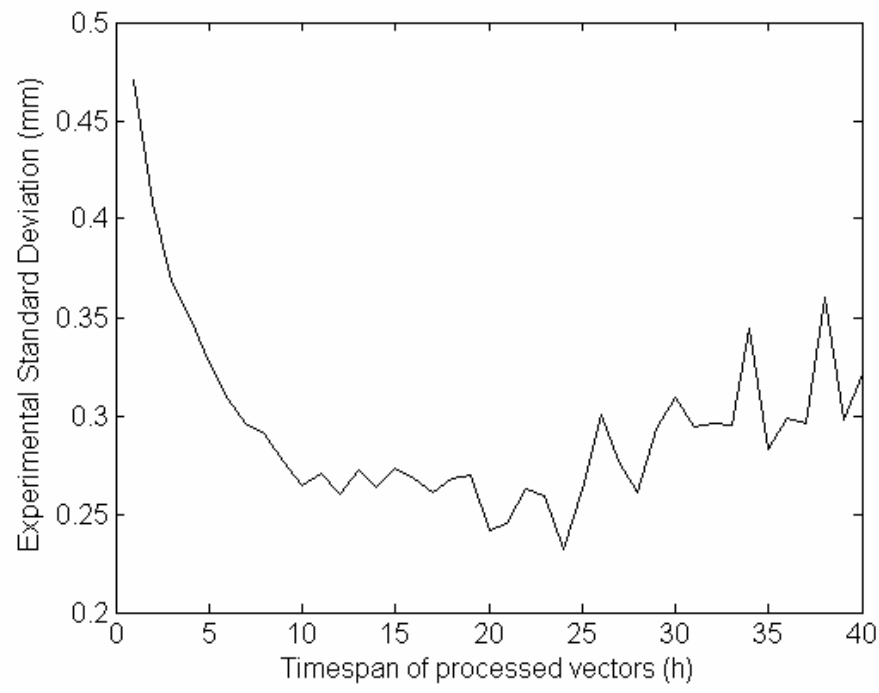

Figure 5. CAGL - CAGZ baseline experimental standard deviations for different timespan data.

As expected, decay stops around $24 \mathrm{~h}$ (roughly speaking, only when processing 24-h we have periodic effects averaged out). We also observe that 10-h timespan data provide also a quite precise estimate, which is a similar result to the one obtained by Hughes et al (2006) for the case of coordinate determination. We can corroborate the existence of a significant sidereal day period by Fourier analysis. Figure 6 displays the amplitude spectrum of the GPS distance annual series, showing the expected significant peak at frequency $1 / 24 \cong 0.0417 \mathrm{~h}^{-1}$.

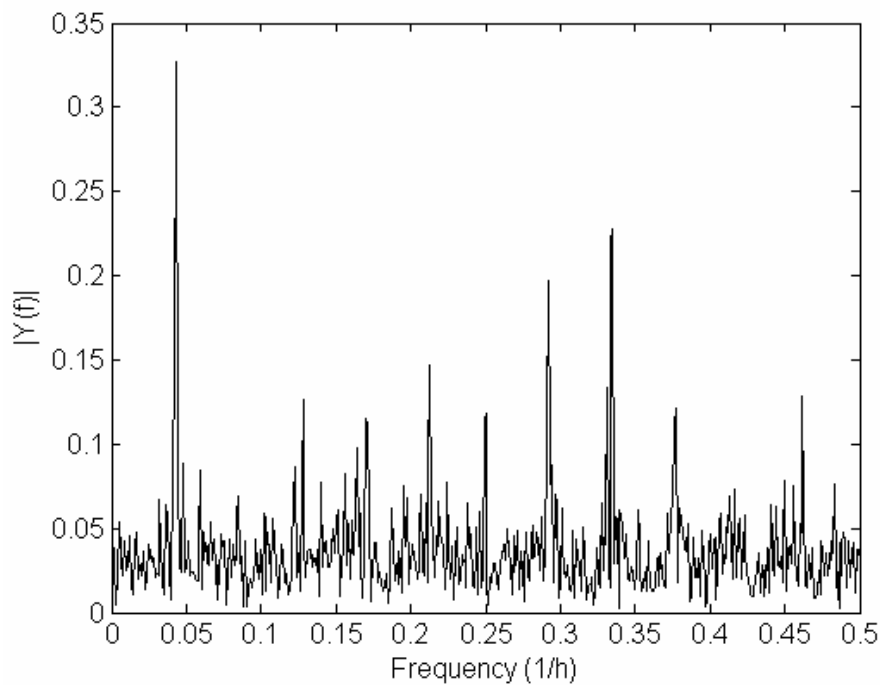


Figure 6. CAGL-CAGZ single-sided amplitude spectrum of measured distances.

So far we have studied the short term variations of baseline length; however there may be some doubts about the determined GPS length being stable in the long term: does the obtained scale vary along months or years?

First of all one must be cautious with changes of antennas, radomes or receivers, since we have experienced significant length changes (several tenths of a millimetre) in these cases. For the finally selected baselines no changes occurred during the processed timespans. We plot in the following figure 7, 8, 9, 10 and 11 the year 2011 monthly averages with respect to the corresponding annual mean of BAY5 - BAY6, LNC1 - LNC2, CAGL - CAGZ, SUTH - SUTM and MEDI - MSEL baselines.

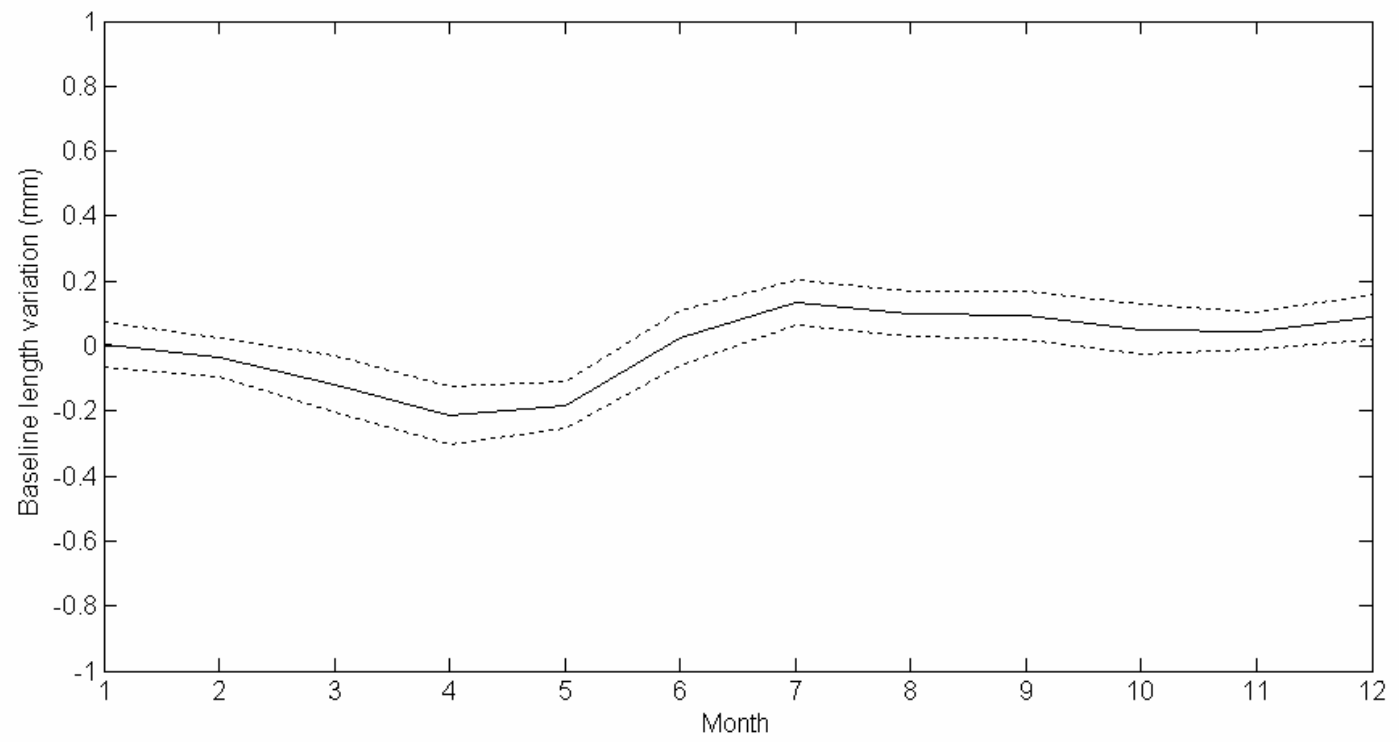

Figure 7. BAY5 - BAY6 monthly averages (dotted lines represent the 95\% confidence level).

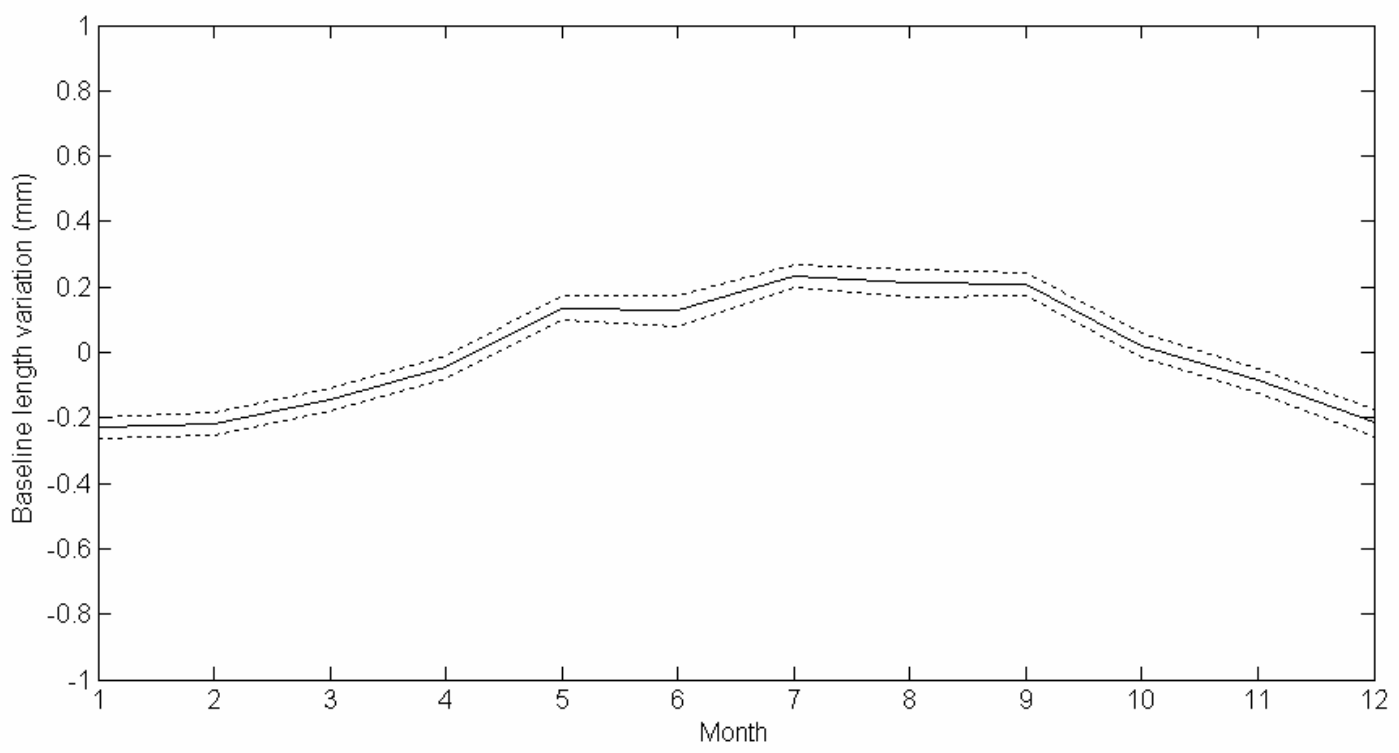

Figure 8. LNC1 - LNC2 monthly averages (dotted lines represent the 95\% confidence level). 


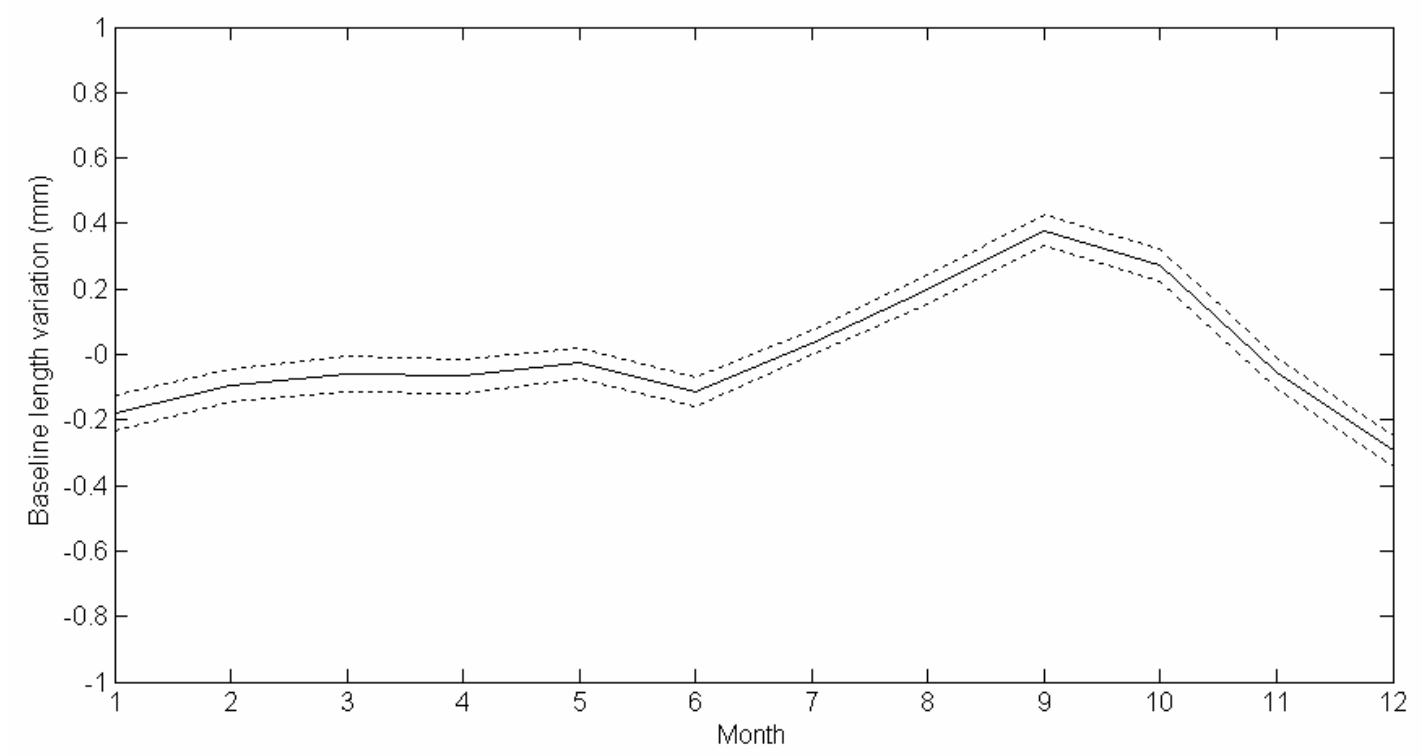

Figure 9. CAGL - CAGZ monthly averages (dotted lines represent the 95\% confidence level).

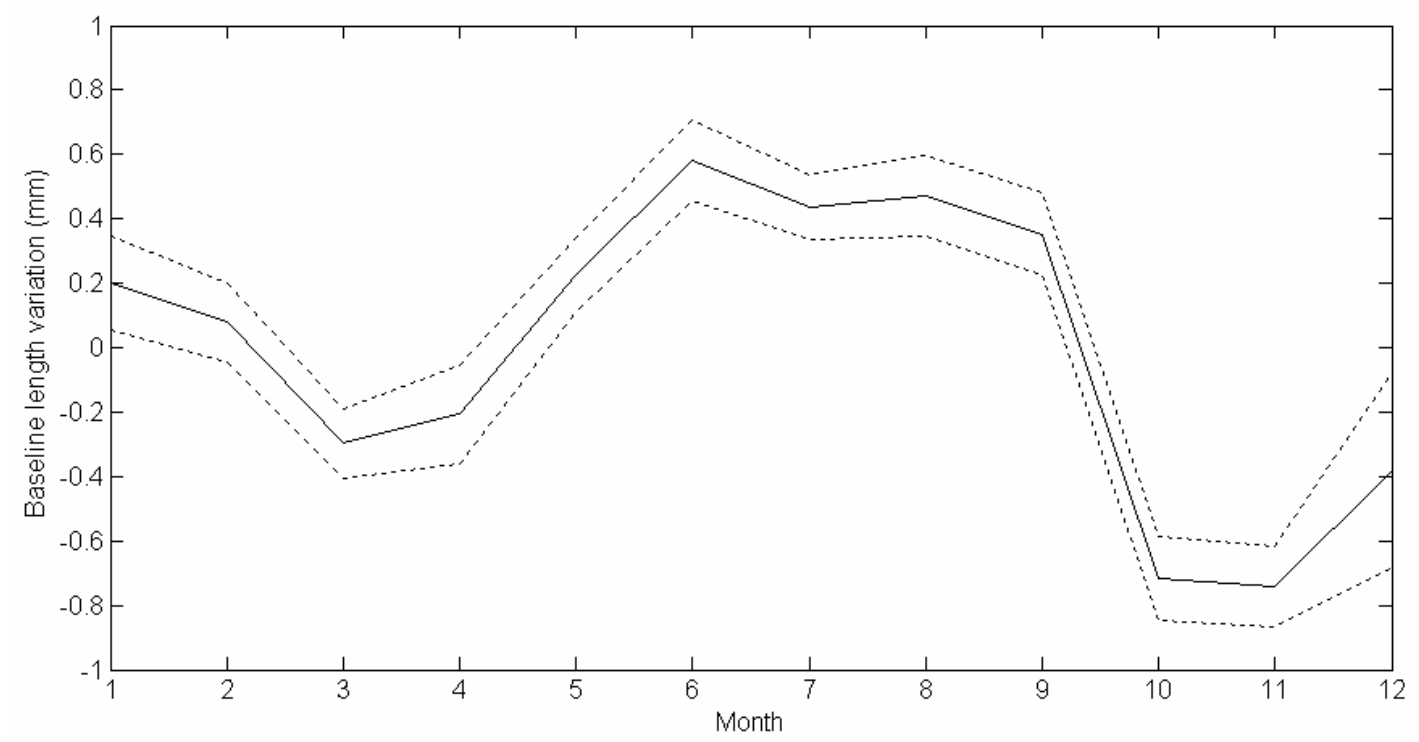

Figure 10 SUTH - SUTM monthly averages (dotted lines represent the 95\% confidence level). 


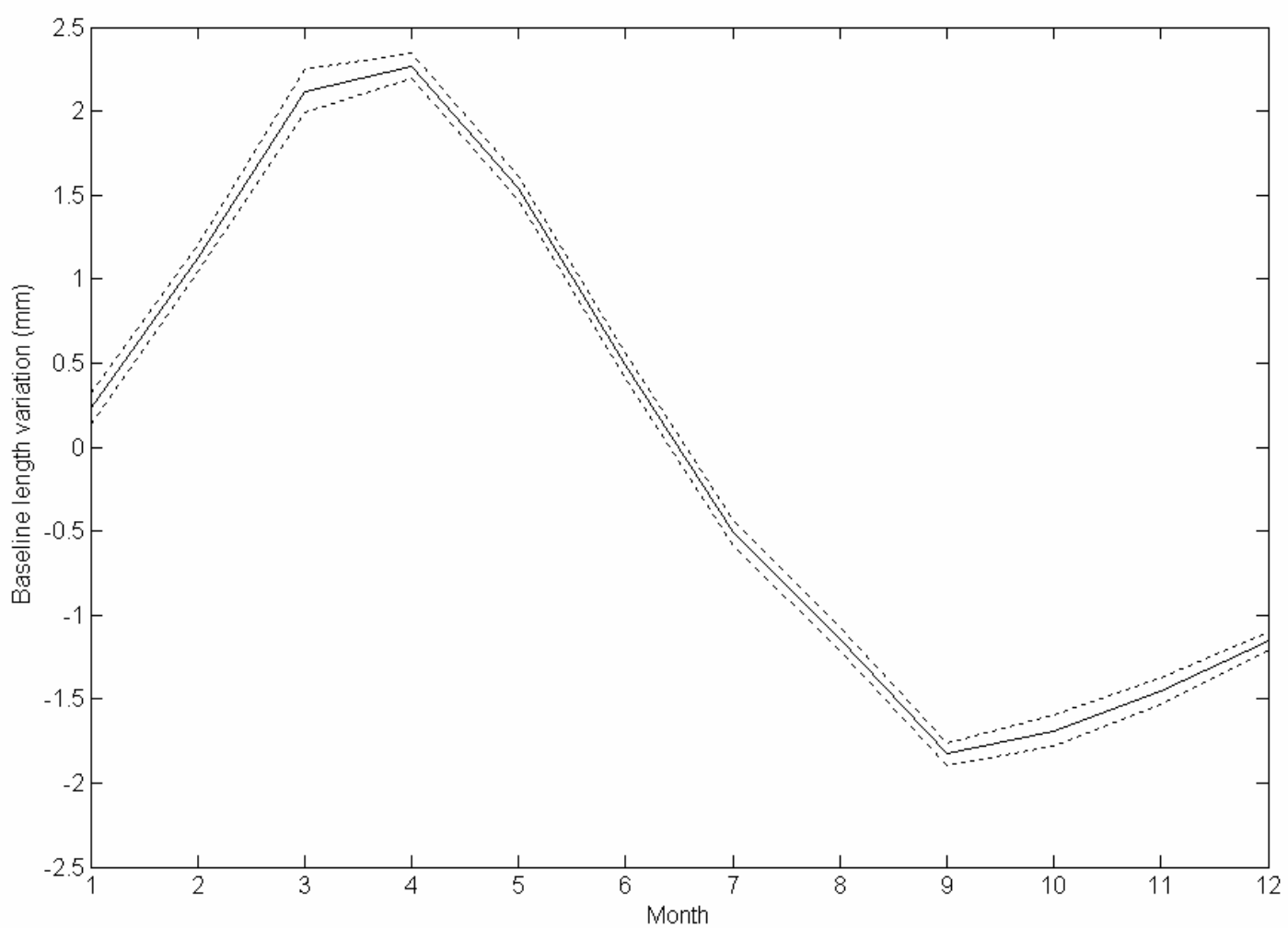

Figure 11. MEDI - MSEL monthly averages (dotted lines represent the 95\% confidence level). Note that yaxis scale is different than previous figures.

The first evident conclusion is that there exist significant - i.e. larger than the obtained uncertainty - systematic effects, more obvious for the last baselines than for the first ones. In particular, note that in figure 11 the length variation is so large that the y-axis range has needed to be extended with respect to the previous figures ( $5 \mathrm{~mm}$ wide for figure 11, while $2 \mathrm{~mm}$ wide for the rest). Secondly, except for figure 11 in which length variations are too large, the rest of baselines show a similar length variation pattern during the year. Consider that despite these baselines are distributed in the entire Earth (different continents and hemispheres: Europe, America, Africa) and different environments they all follow a similar pattern. For the purpose of comparison some of the baselines were also computed for the year 2010 and showed a similar behaviour: we give figure 12 as an example.

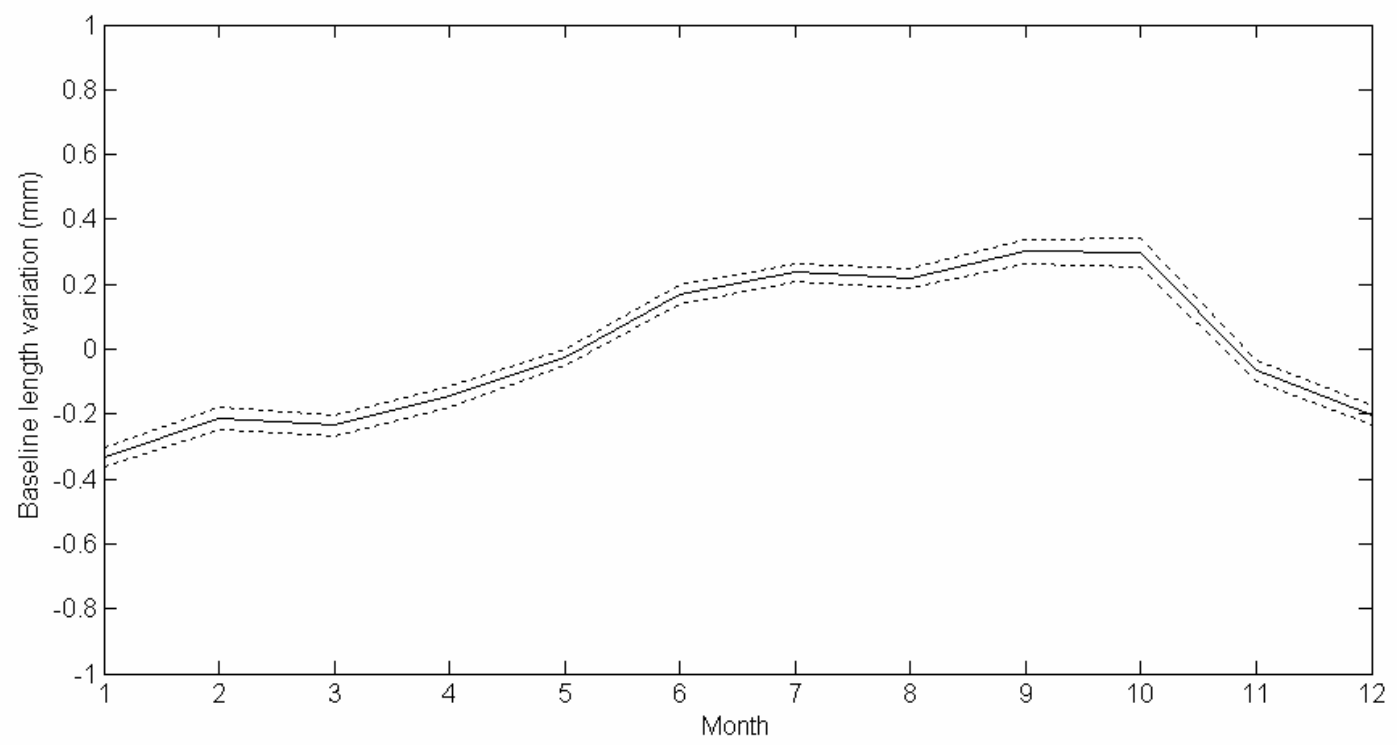


Figure 12. LNC1 - LNC2 monthly averages for year 2010 with respect to year 2011 annual average (compare with figure 8 for 2011; dotted lines represent the 95\% confidence level).

The source of this systematic behaviour is unclear. However, there seems to be a plausible explanation for the different length variation ranges - a maximum deviation from the mean of 0.21 $\mathrm{mm}$ for the best case (figure 7) and $2.27 \mathrm{~mm}$ for the worst (figure 11) - being possibly the reason the use of the same antennas and radomes or the use of different ones, some of them with not very precise calibration corrections.

Hence, the best values are obtained for BAY5 - BAY6 and LNC1 - LNC2, which use the same antennas and radomes in both baseline ends. Baselines CAGL - CAGZ and SUTH - SUTM use different antennas and radomes in the baseline ends and, even if the absolute antenna calibration tables should account for this, the observed distance variation is larger than in the previous cases. Consider, however, the extremely high degree of precision we are aiming at: a few tenths of a millimetre; whereas the absolute antenna calibration table values may have inaccuracies up to 1 mm (Zeimetz and Kuhlmann 2008), enough for the great majority of geodetic and surveying purposes but not for our present objective. Finally we find a plausible reason for the large instability of baseline MEDI - MSEL values (figure 11): not only there are different antennas in both ends but also one of them has only calibration values in terms of the elevation angle (not function of azimuth), which may turn out to be an insufficient calibration for our purposes. These results are summarized in Table 2.

Table 2. Length variation for the different equipment setups.

\begin{tabular}{lcc}
\hline Equipment and calibration & Baseline & $\begin{array}{c}\text { Max. deviation } \\
\text { from mean (mm) }\end{array}$ \\
\hline Same antennas and radomes & BAY5 - BAY6 & 0.21 \\
\hline $\begin{array}{l}\text { Different antennas. } \\
\text { Calibration values } f \text { (azimuth,elevation) }\end{array}$ & CAGL - CAGZ & 0.38 \\
\hline $\begin{array}{l}\text { Different antennas. } \\
\text { Calibration values } f(\text { elevation) }\end{array}$ & MUTH - SUTM & 0.74 \\
\hline
\end{tabular}

In view of this figures one can conclude a clear preference for arrangements with the same antenna and radomes in both baseline ends. It also can be concluded that submillimetric length reproducibility is still possible by means of GPS: some $0.2-0.3 \mathrm{~mm}$ precision results are possible after 24 hours of observation and they may be consistent in the long term within this submillimetric level of precision. However, we recall that we are studying only the reproducibility of GPS distance determination. The question of comparison with the absolute scale - traced to the definition of the metre - remains open for further research and experiments.

\section{Conclusion}

As necessary requirement for the eventual usage of GPS in distance determination over short baselines with submillimetre accuracy, submillimetric reproducibility in GPS distance determination was shown to be a feasible issue under some requirements. The use of the same 
antennas and radomes in both baseline ends was found to be critical for attaining the best reproducibilities, considering that antenna calibration accuracies play a non-negligible role in submillimetric distance determination. The remaining short-term systematic effects were found to be successfully mitigated after a 24-h observation time whereas a significant length consistency in the long term was found below the millimetre level although there still remain some unmodelled systematic effects of the order of a few tenths of a millimetre.

Additional research and experiments in dedicated facilities are required now to be able to compare at the submillimetre level the GPS derived distances with the absolute distances and assess not only their reproducibility but also their accuracy.

Acknowledgments This research is funded by the Spanish Ministry of Science and Innovation (AYA201123232). Authors are grateful to the editor and the anonymous reviewers for their valuable suggestions, corrections and comments that helped improve the original manuscript.

\section{References}

Amiri-Simkooei AR and Tiberius CCJM 2007 Assessing receiver noise using GPS short baseline time series. GPS Solut. 11 21-35

Bell B (Ed.) 1992 Proc. Workshop on the use and calibration of the Kern ME5000 Mekometer. Stanford Linear Accelerator Center, Stanford University, USA, June 18-19

Bona P and Tiberius CCJM 2000 An experimental comparison of noise characteristics of seven high-end dual frequency GPS receiver-sets. Proc. IEEE PLANS2000, IEEE, Piscataway, N.J., 237-244

Bruyninx C, Carpentier G and Roosbeek F 2009 The EUREF Permanent Network: Monitoring and On-line Resources. International Association of Geodesy Symposia 134 131-136. doi: 10.1007/978-3-642-008603_20

Doloca NR, Meiners-Hagen K, Wedde M, Pollinger F and Abou-Zeid A 2010 Absolute distance measurement system using a femtosecond laser as a modulator. Meas. Sci. Technol. 21115302

Dow JM, Neilan RE and Rizos C 2009 The International GNSS Service in a changing landscape of Global Navigation Satellite Systems. J. Geod. 83(3-4) 191-198

Firuzabadi D and King RW 2012 GPS precision as a function of session duration and reference frame using multi-point software. GPS Solut. 16 191-196

Griffits J and Ray JR 2012 Sub-daily alias and draconitic errors in the IGS orbits. GPS Solut. doi: 10.1007/s10291-012-0289-1

Hughes JC, Banks JA, Kerkhoff AJ, Tolman BW and Wyant JR 2006 Sub-millimeter Precision GPS Survey System at the Holloman High Speed Test Track, 19th International Technical Meeting of the Satellite Division of the Institute of Navigation (ION GNSS 2006). Fort Worth, Texas. September 26-29

Hyun S, Kim YJ, Kim Y, Jim J and Kim SW 2009 Absolute length measurement with the frequency comb of a femtosecond laser. Meas. Sci. Technol. 20095302

Jokela J and Häkli P 2006 Current research and development at the Nummela standard baseline. XXIII FIG Congress, Munich, Germany, October 8-13.

Koivula H, Häkli P, Jokela J, Buga A and Putrimas R 2012 GPS metrology: bringing traceable scale to local crustal deformation network. In: Kenyon S, Pacino MC, Marti U (Ed) Geodesy for Planet Earth, International Association of Geodesy Symposia 136 Part 1 105-112, Springer-Verlag Berlin Heidelberg.

Lassila A, Jokela J, Poutanen M and Jie X 2003 Absolute calibration of quartz bars of Väisälä interferometer by white light gauge block interferometer. XVII IMEKO World Congress, Metrology in the 3rd Millennium, Dubrovnik, Croatia, June 22-27

Ray J, Altamimi Z, Collilieux X and van Dam T 2008 Anomalous harmonics in the spectra of GPS position estimates. GPS Solut. 12 55-64

Schuhler N, Salvadé Y, Lévêque S, Dändliker R and Holzwarth R 2006 Frequency comb referenced twowavelength source for absolute distance measurement. Opt. Lett. 31 3101-3103 
Snay RA and Soler T 2008 Continuously Operating Reference Station (CORS): History, Applications, and Future Enhancements. J. Surv. Eng. 134(4) 95-104

Wallerand J P, Abou-Zeid A, Badr T, Balling P, Jokela J, Kugler R, Matus M, Merimaa M, Poutanen M, Prieto E, van den Berg S and Zucco M 2008 Towards new absolute long distance measurement systems in air. NCSL International Workshop and Symposium, Orlando, USA, August 3-7

Zeimetz P and Kuhlmann H 2008 On the accuracy of absolute GNSS antenna calibration and the conception of a new anechoic chamber. FIG Working Week, Stockholm, Sweden, June 14-18. 